\title{
IMPLICAÇÕES DA DIDÁTICA NA PRÁTICA DOCENTE DE PROFESSORES DO ENSINO SUPERIOR: CONTRIBUIÇÕES DA PESQUISA-AÇÃO COLABORATIVA.
}

\author{
Letícia de Oliveira Cerqueira ${ }^{1}$; Amali de Angelis Mussi²; \\ 1. Bolsista FAPESB, Graduando em Letras vernáculas, Universidade Estadual de Feira de Santana, e-mail: \\ leticiaocerqueira@hotmail.com \\ 2. Orientador, Departamento de Educação, Universidade Estadual de Feira de Santana, e-mail: amalimussi@uefs.br
}

PALAVRAS-CHAVE: Aprendizagem no ensino superior. Docência universitária. Pedagogia Universitária.

\section{INTRODUÇÃO}

Nesse resumo expandido, apresentamos um recorte dos dados obtidos através da pesquisa "Implicações Da Didática Na Prática Docente De Professores Do Ensino Superior: Contribuições Da Pesquisa-Ação Colaborativa”. O objetivo da investigação consiste em compreender as contribuições da didática na formação dos professores do ensino superior, identificando como se dá a utilização de recursos didáticos por professores do ensino superior. Para o estudo partimos da premissa de que na atualidade, o ensino superior brasileiro vivencia diferentes desafios, produzidos por processos de mudança de ordem social, econômica e política, ocorridos nas últimas décadas no contexto mundial. Nesse contexto encontram-se também as mudanças históricas produzidas pelas lutas da sociedade a favor da democratização do acesso ao ensino superior, com a conquista de políticas educacionais orientadas para a busca da equidade social, permitindo a inclusão de camadas sociais e culturais plurais, com novas linguagens, necessidades e experiências. Esses processos de mudanças incidem sobre toda sociedade e de forma contundente provocam novas configurações sobre a formação e prática do professor que atua no ensino superior.

Dentre os atuais desafios, há, no ensino superior, a expectativa do docente se colocar numa posição de mediador e facilitador da aprendizagem, estimulando e organizando conhecimentos a partir da interação com os alunos para que faça sentido para os mesmos. Porém deixar de centrar no docente como detentor do saber e a utilização do ensino tradicional para centrar na utilização de recursos didáticos que estimulam os alunos, facilitando e enriquecendo o processo de ensino e aprendizagem, ainda é uma tarefa árdua e processual. A questão real é qual a contribuição da Didática para a formação desse profissional? E quais têm sido seus desafios e perspectivas? Assim, buscamos investigar como a didática vem contribuindo para a formação do professor universitário e na construção de sua identidade profissional.

A discussão agrega-se aos estudos que já vem sendo desenvolvidos pelo Núcleo de Estudo e Pesquisa sobre Pedagogia Universitária (NEPPU) intitulada "Inovação da prática pedagógica de professores do ensino universitário pela pesquisa-ação colaborativa", em uma Universidade Pública do interior da Bahia.

\section{MATERIAL E MÉTODOS OU METODOLOGIA (ou equivalente)}

Para a coleta de dados, realizamos uma entrevista semiestruturada com 5 (cinco) questões abertas e apreendemos os relatos dos professores (todos transcritos) durante a 
reunião do Núcleo de Estudos e Pesquisa sobre Pedagogia Universitária (NEPPU). O estudo realizado é de cunho qualitativo, a qual dizem respeito a compreensão de que modo o docente universitário ensina, identificação das contribuições da didática para tornar-se professor e examinar dos seus conhecimentos acerca da didática.

Os dados produzidos na pesquisa passaram por um processo de análise de conteúdo do tipo temática (BARDIN, 1997), que se constitui de uma método que possibilita compreender mais profundamente as representações sociais dos professores sobre o objeto estudado permitindo a interpretação dos dados a partir da influência da linguagem cultural e os seus significados, e ao pesquisador permite que faça uma interpretação pessoal da percepção dos dados.

Apoiando-se na proposta de análise de Bardin (1997), os dados produzidos foram categorizados e estudados através de uma tabela de análise teórica. As categorias foram criadas a partir de palavras e/ou sentidos encontrados nos relatos dos professores que deram o norte para iniciar o trabalho: processo de aprendizagem, estratégias de ensino aprendizagem, concepções de aprendizagem, prática docente, conteúdo e características de aprendizagem; o que nos possibilitou a construção de duas categoria em que uma delas possuem subcategorias para fundamentar e complementar ainda mais nossa discussão.

Os dados foram categorizados em uma dimensões e se desdobram em algumas subdimensões: 1- Reflexão sobre a prática docente dos docentes participantes da pesquisa-ação colaborativa, subdimensões: 1.2 Didática enquanto campo epistemológico; 2-Formação do professor universitário, subdimensões; 1.3 Didática: refletir, ensinar, aprender 2.1 Construção identitária do docente universitário sujeitos da pesquisa. Constituíram-se sujeitos desta pesquisa 04 (quatro) docentes da Universidade estadual de Feira de Santana - UEFS.

Os sujeitos foram identificados nessa pesquisa como P1, P2, P3 e P4. Optamos por não revelar a identidade pessoal dos mesmos e sim abarcar a identidade profissional no viés da própria prática docente.

\section{RESULTADOS E/OU DISCUSSÃO (ou Análise e discussão dos resultados)}

Através de pesquisas e análises constatamos que a didática é a ciência em que o processor concentra e unifica saberes profissionais a serem mobilizados para a ação docente, saberes constituídos por conhecimentos relacionados aos processos de ensino e aprendizagem na garantia de uma excelente formação dos alunos. De acordo com Cruz (2017), competem as responsabilidades da didática as teorizações e fundamentações conceituais e procedimentais com base no conhecimento em situações que envolvam o ensinar e o aprender.

Nossos sujeitos da pesquisa possuem concepções de didática controversas, a exemplo temos o docente $\mathrm{P} 1$ que reconhece a didática como um conjunto de técnicas de ensino que favoreçam a aprendizagem, já o docente $\mathrm{P} 2$ acredita didática não é uma metodologia com uma técnica engessada do ensinar e que existe uma confusão nesse campo teórico de estudo. Assim, de acordo com o docente $\mathrm{P} 2$, o fato do professor não ter didática não significa que ele não tem uma técnica específica e não possui metodologia, acreditando que por vezes falta ao professor o domínio mesmo de estratégias, de técnicas, mas não lhe falta o domínio do conteúdo, por essa razão pressupõe que na anseio da didática o professor precisa inserir-se no processo

Nossos dados revelaram que a didática orienta e assegura a unidade entre o aprender e o ensinar na relação com o saber em situação contextualizada, nas quais os alunos são orientados em atividades autônomas pelos professores. Os docentes, sujeitos dessa pesquisa buscam no ato de ensinar mediar a aprendizagem dos seus alunos, embora 
alguns relataram que seja um imenso desafio, como forma de garantir o aprendizado nossos sujeitos inventem na criatividade e estratégias didáticas para modificar suas práticas. Assim, visando um bom ensino os docentes adotam recursos didáticos tanto para dar aula quanto para a disciplina a qual lecionam na universidade.

Constatou-se, ainda, no presente estudo que é no processo de ensino que o professor se apropriará e aplicará o conhecimento para que seus alunos desenvolvam capacidades intelectuais, e através das práticas de ensino o professor se constituirá dos saberes profissionais inseridas nos contextos socioculturais e intencional. Desta forma, ao estudar a didática é necessário pensar no profissional, o docente que a utiliza.

A identidade do professor constitui-se através de um processo sócio histórico, isto é, está vinculada a humanização e articulação com diversas experiências ao longo da vida profissional e pessoal (FARIAS et al., 2011). A docente P1 nos revelou que se constituiu professor através de lugares em que trabalhou e havia orientações e oficinas didáticas, $\mathrm{O}$ docente P2 demonstrou que a sua experiência na educação básica, na escola pública, trabalhando no noturno e sua relação com os estudantes o constituiu professor; já o docente P3 considerou fundamental a sua a experiência vivida como professora de catecismo na igreja para iniciar a formação de seus primeiros alunos.

A identidade e o fazer docente são elementos importantes para o docente, ele é o profissional responsável pela concretização do processo de ensino. O professor delibera apoiado em experiências e teorias a qual estudou, mantendo assim relação e comprometimento com a instituição, a sociedade e com o conhecimento (FARIAS et al., 2009). Por fim, percebemos que nossos sujeitos, atuantes no ensino superior, identificam-se com sua área de atuação e não como professor do curso que leciona.

\section{CONSIDERAÇÕES FINAIS (ou Conclusão)}

Ao longo desta pesquisa pretendeu-se enfatizar a importância da didática na formação dos docentes de ensino superior para a melhoria do seu trabalho acadêmico. Concretamente, isso nos levou a concluir que a didática implica impreterivelmente a prática e cabe ao docente articular o processo de ensino-aprendizagem. A identidade também é um fator importante ao trabalho docente em virtude de assegurar elementos instrumentais e fundamentais ao desempenho dos procedimentos e estratégias didáticas no seu fazer docente.

Todos os docentes reconhecem a importância e valorizam a didática e seus recursos em suas atuações docentes e ainda acrescentam que já possuíram perfis semelhantes a de alguns colegas da profissão que não se preocupam com o fato de ter ou não didática e acreditar que saber e dominar o conteúdo é suficiente para a tarefa de ensina, entretanto hoje se reconhecem totalmente diferentes e abetos e flexíveis a mudanças de postura e amadurecimento profissional.

\section{REFERÊNCIAS}

ABDALLA, M. F. B. O sentido do trabalho docente e a profissionalização: representações sociais dos professores formadores. In: SOUSA, C. P.; PARDAL, L. A.; VILLAS BÔAS, L. P. (Org.). Representações sociais sobre o trabalho docente. Aveiro: Universidade de Aveiro, 2009. p. 171-182.

BARDIN, Laurence. Análise de conteúdo. Lisboa: Edições 70, 1997. 
CRUZ, Gisele Barreto da. Didática e formação de professores. Cadernos de Pesquisa v.47 n.166 p.1100-1105 out./dez. 2017.

CRUZ, Gisele Barreto da. Didática e docência no ensino superior. Rev. bras. Estud. pedagog., Brasília, v. 98, n. 250, p. 672-689, set./dez. 2017.

IBIAPINA, Ivana Maria. Pesquisa colaborativa: investigação, formação e produção de conhecimentos. Brasília, DF: Ed. Liber Livro, 2008.

LENOIR,Yves; LAFOREST, Mario (Dir). La bureaucratisation de la recherche en education et en sciences sociales. Constats, impacts et conséquences. Revue fraçaise de pédagogie, 1998, v. 123, n.123, pp.176-178.

LOUIS, Roland. Inovação pedagógica no ensino superior. In: CUNHA, M. I. da; SOARES, S. R.; RIBEIRO, M. L. (Orgs.). Docência universitária: profissionalização e práticas educativas. Feira de Santana: UEFS editora, 2009.

LIBÂNEO, José Carlos. O campo teórico- investigativo e profissional da didática e a formação de professores. In: RAJADELL, N. e SUANNO, M. Didática e formação de professores: perspectivas e inovação. Goiânia: CEPED Publicações e PUC Goiás, 2012, p. 32-58.

MASETTO, Marcos Tarcísio. Competências pedagógicas do professor universitário. São Paulo: Sumus, 2003.

MASETTO, Marcos Tarcísio (org). Docência Universitária. Campinas, SP: Papirus, 1988.

MIRANDA, M. G.; RESENDE, A. C. A. Sobre a pesquisa-ação na educação e as armadilhas do praticismo. Revista Brasileira de Educação, v. 11, p. 511-518, 2006.

RAJADELL, Núria. A importância das estratégias didáticas em toda ação formativa. In: RAJADELL, N. e SUANNO, M. Didática e formação de professores: perspectivas e inovação. Goiânia: CEPED Publicações e PUC Goiás, 2012, p. 105-132.

SOBRINHO, José Dias. Professor universitário: contextos, problemas e oportunidades. In CUNHA, Maria Isabel; SOARES, Sandra Regina; RIBEIRO, Marinalva Lopes (Orgs.). Docência Universitária: profissionalização e práticas educativas. Feira de Santana: UEFS Editora, 2009. p. 15-31.

TEJADA. José. Inovação didática a universidade: alternativas na formação de professores. In: RAJADELL, N. e SUANNO, M. Didática e formação de professores: perspectivas e inovação. Goiânia: CEPED Publicações e PUC Goiás, 2012, p. 59-78.

ZABALZA, M.A. O ensino universitário: seu cenário e seus protagonistas. Porto Alegre: Artmed, 2004. 